\title{
O desenvolvimento da marca de um país: é possível estimular o reconhecimento internacional de um Brasil tecnológico e inovador?
}

The development of country-branding: Is it possible to stimulate the international recognition of a technological and innovative Brazil?

DOI: https://doi.org/10.22456/2178-8839.111411

Luis Fernando Corrêa da Silva Machado

Ministério das Relações Exteriores, Brasília, Brasil

lfcsmachado@gmail.com

\section{Resumo}

Este artigo analisa as razões de esforços empreendidos para promover a narrativa de um Brasil tecnológico e inovador no exterior. A premissa é de que países investem em iniciativas de diplomacia pública e marketing a fim de melhorar a inserção internacional de produtos, serviços ou processos tecnológicos, bem como a atração de investimentos e mão de obra qualificada estrangeiros. O propósito da pesquisa é o de identificar limitações e fortalezas da diplomacia pública brasileira para se alcançar o desenvolvimento da marca-país no setor de tecnologia. Trata-se de pesquisa exploratória, que recorre à análise de bibliografia especializada e de estratégias adotadas por cinco países (Estônia, Índia, Suécia, Suíça e Reino Unido), para fins ilustrativos, com vistas à compreensão do problema. Concluiu-se que para que se atinja esse objetivo a atuação da Chancelaria não é suficiente. Todos os órgãos do governo, em níveis federal, estadual e municipal e, de preferência, também do empresariado e da sociedade civil deveriam estar envolvidos. Este trabalho sugere que o SICOM concentre o processo decisório da formulação e implementação da política da marca-Brasil, inclusive do componente tecnológico.

Palavras-chave: Diplomacia pública; Marca-país; Promoção tecnológica;

\section{Abstract}

This article seeks to understand the reasons of the efforts to promote the narrative of a technological and innovative Brazil abroad. The premise is that countries invest in public diplomacy and marketing initiatives, in order to improve the international insertion of technological products, services or processes, as well as the attraction of foreign investments and qualified workers. The purpose of the research is to highlight the constraints and strengths of Brazilian public diplomacy in order to achieve the goal of developing the country brand related to the technological sector. This is an exploratory research, which resorts to the specialized bibliography and to the assessment of the strategies adopted by five countries (Estonia, India, Sweden, Switzerland and the United Kingdom), for illustrative purposes, to better understand the problem. It was concluded that, in order to achieve such objective, the work performed by the Chancellery is not enough. All government agencies, at federal, state and municipal levels, and preferably also business and civil society should be involved. This work suggests that SICOM should concentrate the decision-making process and initiatives related to the country-branding of Brazil, including the technology component.

Keywords: Public diplomacy; Country branding; Technology promotion; 


\section{Introdução}

A falta de reconhecimento do Brasil no cenário internacional como nação inovadora gera externalidades negativas que prejudicam a inserção internacional de produtos, serviços ou processos tecnológicos inovadores nacionais, bem como a atração de investimentos e mão de obra qualificada estrangeiros. É, portanto, benéfico que os países invistam em esforços de diplomacia pública e marketing para melhorar sua imagem e reputação.

A questão relacionada à falta de identificação da marca ${ }^{1}$ Brasil com tecnologia é suscitada por especialistas internacionais. Em evento realizado em São Paulo, em 2018, antes da publicação do “Índice Global de Inovação” (IGI) daquele ano, o professor da Universidade de Cornell, Soumitra Dutta, um dos editores do IGI e um dos mais respeitados especialistas em inovação no mundo, destacou em sua apresentação conjunto de dificuldades que o Brasil precisa vencer para ser bom exemplo em inovação, bem como caminhos para superar tais barreiras. Entre esses desafios, o professor Dutta singularizou que a marca Brasil, apesar de forte, teria baixo valor com relação à inovação. Em 2020, em evento promovido pela Confederação Nacional das Indústrias (CNI), Dutta novamente recomendou que o governo busque estabelecer colaboração entre os diferentes atores dos ecossistemas nacionais de inovação com o objetivo de construir uma marca de país inovador no plano internacional. Segundo o especialista, "a inovação é uma corrida mundial, em que os países competem entre si pelo sucesso global”.

A mesma constatação foi evidenciada nas oficinas do Ministério da Ciência, Tecnologia e Inovações (MCTI) para a formulação da Política Nacional de Inovação, realizadas entre o final de 2019 e o início de 2020, nas quais, entre as ações identificadas para superar os atuais desafios no estímulo à inovação, foi destacada a de "promover o Brasil no cenário internacional como nação inovadora”. Trata-se, portanto, de anseio dos integrantes do Sistema Nacional de Ciência, Tecnologia e Inovação (SNCTI) ${ }^{3}$ a correção desse “déficit de imagem” do Brasil na área tecnológica.

Neste artigo de caráter exploratório, com o intuito de compreender os esforços empreendidos para promover a narrativa de um Brasil tecnológico e inovador no exterior, a pesquisa recorreu tanto à análise da literatura especializada quanto das estratégias adotadas, a título ilustrativo, por cinco países cujas reputações internacionais estão associadas à tecnologia e à inovação a fim de compreensão do problema. Nesse contexto, serão tratadas, inicialmente, as diferentes abordagens sobre o relacionamento entre diplomacia pública e desenvolvimento da marca-país, a fim de compreender o papel das chancelarias em influenciar a percepção de agentes estrangeiros sobre as capacidades tecnológicas de suas respectivas nações.

Nesse contexto, serão analisados conceitos como o de diplomacia pública, "efeito país de origem”, marca-país, bem como discutidos os fenômenos do "déficit de imagem”, que geram percepções equivocadas, e da criação de relações de confiança para a construção de parcerias e atração de investimentos estrangeiros. Em seguida, será conferido destaque à gestão da imagem de um país inovador, que apresenta características distintas de outros segmentos, a exemplo do turístico. Posteriormente, serão comentadas, estratégias adotadas por Estônia, Índia, Suécia, Suíça e Reino Unido. Por fim, serão tecidas considerações sobre o Programa de Diplomacia da Inovação (PDI) do Itamaraty e a própria atuação da Chancelaria brasileira, que busca promover no exterior uma nação tecnológica inovadora e reunidas as principais conclusões do trabalho.

\footnotetext{
${ }^{1}$ Andreucci Cury (2015), em sua tese de doutorado, explica que: "talvez pela imbricação do conceito de país com o de nação e a impossibilidade de dissociar um país de seu povo, da sua cultura, nas várias bibliografias sobre o tema, os termos marca-país e marca-nação, com ou sem hífen, surgem indiscriminadamente para definir o conceito e a prática de 'branding' de um país”. Este artigo adota o termo marca-país. A opção de utilizar palavra composta, separada por hífen, parte do pressuposto que as duas palavras juntas criam novo termo.

${ }^{2}$ Elaborado pela OMPI juntamente com a Universidade de Cornell e o INSEAD, em 2020 na sua 13a edição, o IGI é padrão global que ajuda os formuladores de políticas públicas a entender como incentivar e mensurar as atividades inovadoras, que constituem um dos principais motores do desenvolvimento econômico e social. O IGI 2020 classificou 131 economias com base em 80 indicadores.

${ }^{3}$ O Art. 219-B da Constituição Federal estabelece que: "O Sistema Nacional de Ciência, Tecnologia e Inovação será organizado em regime de colaboração entre entes, tanto públicos quanto privados, com vistas a promover o desenvolvimento científico e tecnológico e a inovação.”
} 


\section{Posicionamento e gestão da marca-país: considerações}

Marca-país e "efeito país de origem"

Não só países, mas regiões e cidades competem na esfera internacional, cada vez mais acirradamente, pela atração de investimentos e de mão de obra qualificada e pela comercialização de seus bens e serviços (ANHOLT, 2007). Para lograr êxito nesses objetivos, os governos recorrem à concessão de benefícios fiscais, e outros tipos de incentivos. No entanto, elementos como as condições e a qualidade de vida locais, e a abundância e a qualidade dos fatores de produção, como recursos naturais e humanos, são crescentemente determinantes nas decisões de escolha da fixação de talentos humanos e investimentos produtivos (DINNIE, 2011). Nesse conjunto de fatores, a depender do segmento econômico, o Brasil sobressai em diversas dimensões (SOUZA et al, 2014).

Para uma nação ser competitiva em termos globais, contudo, é fundamental que haja constante comunicação para o público externo de suas vantagens comparativas, com vistas a que não seja criada desconexão muito significativa entre a imagem que as pessoas têm de um país da sua realidade. Por imagem externa de um país, entende-se o conjunto de percepções de indivíduos e entidades estrangeiras a respeito das características e identidade de uma determinada nação (MOURA, 2013). Trata-se da reputação frente à opinião internacional (HAM, 2001).

Muitas vezes há forte descompasso ou mesmo deturpação da imagem que cerca um país de sua realidade, o chamado “déficit de imagem” (BARROSO, 2007). Os estereótipos sejam negativos ou positivos são criados pela simplificação da realidade, que decorre da impossibilidade de que um indivíduo ou grupo de indivíduos se mantenham atualizados sobre o que passa nas mais diferentes dimensões (cultural, política, econômica, científica) em todo o planeta. A tarefa de competir pelo espaço nas mentes e emoções das pessoas, a fim de dar ensejo a percepções positivas, recai sobre os representantes de cada país, ou seja, cidadãos, empresas, organizações, mas, em particular, os governos, que são responsáveis por esse interesse difuso maior de que seus cidadãos sejam respeitados e, se possível, admirados por qualidade positivas, desde que condizentes com a realidade. Anholt ${ }^{4}$ (2007) alerta que nem sequer haveria muita opção aos governos, pois se esses não assumem o papel de gestão de suas marcas-país, outras entidades e nações consolidam as reputações nacionais com base em clichês e estereótipos superficiais.

Em geral, cada povo acaba por ter um conjunto de características principais no imaginário coletivo, uma "marca", que sintetiza a opinião sobre determinada nação. Se essa simplificação da realidade for considerada positiva, em geral, será transmutada para os diversos aspectos de recursos provenientes daquele lugar, sejam produtos, pessoas ou ideias. Por sua vez, em caso negativo, pode criar barreira difícil de se transpor.

Diversos estudos sobre o "efeito país-de-origem” aplicado ao comércio internacional proliferaram na literatura especializada (KOTLER; GERNER, 2002; GILMORE, 2002; SZONDI, 2007; PARAIZO, 2007; BRIJS, 2009; SAME; SOLARTEVAZQUES, 2014; MARIUTTI, 2015; MONTANARI; GIRALDI, 2018). Esse fenômeno associa o local de proveniência dos produtos com determinadas representações mentais. Essas crenças e concepções em relação à determinada região e ao que dela é originado, apesar de distintas, estão relacionadas, uma vez que a reputação da nação afeta a imagem de seus bens e serviços e acaba por ser critério de escolha pelos consumidores (HAKALA; LEMMETYINEN; KANTOLA, 2013), que precisam simplificar as variáveis na avaliação de suas decisões do dia a dia.

\footnotetext{
${ }^{4}$ Anholt (2005) começou a criticar a exploração do uso comercial de marca, na expressão marca-país, para denominar as atividades de gestão de imagem das nações e cunhou o termo "identidade competitiva", pelo qual defende o posicionamento do país, por meio de ações de diplomacia pública, ao concentrar sua identidade nacional em seis pontos principais, um hexágono: i) turismo, ii) população, iii) cultura, iv) investimentos, v) políticas públicas e vi) marcas dos produtos de exportações. Este trabalho, contudo, considera que a promoção da marca-país é uma das atividades da diplomacia pública. Cabe, portanto, coordenação entre as Chancelarias e as entidades responsáveis pela formulação e execução da marca-país no exterior. $\mathrm{O}$ assunto será detalhado na seção 1.3 .
} 


\section{Gestão da marca-país}

A gestão da marca-país compreende o acompanhamento da avaliação da opinião pública internacional sobre determinada nação (OLINS, 2002), bem como as ações direcionadas para a modificação de percepções equivocadas e para realçar determinadas características positivas e pontos fortes, que passam despercebidas por agentes externos, além da mensuração do impacto dessas atividades sobre os públicos-alvo. Sua gestão apropriada acarreta ganhos competitivos aos países, além de antecipar oportunidades e riscos para a reputação no exterior que terão reflexos econômicos internos (WHITE; KOLESNICOV, 2015).

Por isso, na defesa de seus interesses, os governos passaram a se preocupar com o gerenciamento, a formulação de estratégias nacionais, e a definição da marca-país (Günek, 2018). É objeto de atenção, igualmente, a coordenação das comunicações desse posicionamento de marca no plano internacional por meio de canais adequados, bem como designações de agências ou órgãos específicos para sua execução, monitoramento e análise dos resultados alcançados. As crises de imagem, se não puderem ser contornadas, poderão ter seus danos reduzidos com o correto emprego de instrumentos de comunicação e gestão de imagem nos momentos apropriados.

Vale sempre reforçar que a gestão da marca-país deverá basear-se nos traços da identidade do território e da população, por meio de estudo de quais seriam as fortalezas e vantagens comparativas dessa nação (FRIMPONG; AUSTIN, 2011). Numa segunda etapa, essa análise deverá verificar se essa identidade está traduzida em termos de imagem externa, de sua reputação, ou se são necessárias ações de comunicação para mostrar ao mundo exterior as características que não são bem compreendidas e, dessa forma, melhorar o posicionamento da marca-país (DINNIE, 2008). Em sua gestão, devese aproximar a imagem que os outros têm do país de sua realidade. Afasta-se, portanto, a conotação negativa da palavra "propaganda”, empregada em inglês, cujas técnicas estão mais preocupadas com o resultado da persuasão do que com a correspondência com a verdade (BAINES; O’SHAUGHNESSY, 2014).

Nye (2008), ao discorrer sobre diplomacia pública como instrumento de poder brando ('soft power'), alerta que, na política internacional, a credibilidade se torna recurso de poder ainda mais importante em razão do "paradoxo da abundância” ${ }^{5}$. Qualquer informação que aparenta ser mera "propaganda” pode não só ser desprezada pelo público, mas também ser contraprodutiva e abalar a credibilidade da reputação de determinada nação.

\section{Diplomacia pública e marca-país}

A gestão da marca-país é considerada exercício de longo prazo (OLINS, 2002), a qual deve estar necessariamente alinhada com a estratégia nacional de desenvolvimento do país e envolver não só os membros do governo, mas a sociedade como um todo. As chancelarias envolvem-se nessa atuação por meio das ferramentas de diplomacia pública, que na definição de Gilboa $(2001,4)$ é "uma comunicação direta com os povos estrangeiros, com o objetivo de afetar o seu pensamento e, em última instância, de seus governos”. Trata-se de atuação adotada por muitos países para avançar seus interesses no plano externo (VILLANOVA, 2002). Seu emprego para a gestão da imagem dos povos não é, contudo, unanimidade.

Melissen (2005) ressalva que, muitas vezes, governos menosprezam programas de diplomacia pública relacionados à gestão da imagem do país e criticam seus gastos, justamente por não apresentarem resultados mensuráveis imediatos. De fato, um dos desafios na aferição da eficácia das ações de diplomacia pública na promoção da marca -país é o lapso temporal demandado para que haja alteração de percepções por parte de segmentos de público estrangeiros, e que essas mudanças de atitude gerem resultados em termos econômicos, políticos, culturais, tecnológicos. É período temporal

\footnotetext{
${ }^{5}$ No "paradoxo da abundância", o imenso volume disponível de informação acarreta escassez de atenção. Quando as pessoas são sobrecarregadas com uma enorme quantidade de dados, é difícil focar em algo específico. Atenção, em vez de informação, torna-se recurso escasso.
} 
que transcende o mandato de governos e que, por isso, muitas vezes, não interessa a políticos que não vão auferir os méritos dos frutos decorrentes dessas iniciativas.

Especialistas no assunto (OLINS, 2002; MELISSEN, 2005; ANHOLT 2007) debatem qual seria o relacionamento entre gestão da marca-país, que é um exercício de relações públicas, e diplomacia pública, e mesmo se haveria alguma diferença entre os dois conceitos. Afinal, no tocante à gestão da marca-país, os profissionais de relações públicas, contratados por governos, e os da diplomacia pública, em geral funcionários públicos, frequentemente buscam os mesmos objetivos, quais sejam, o de influenciar as opiniões públicas internacionais. De fato, diplomacia pública e gestão da marca de um país compartilham similaridades, mas apresentam ao mesmo tempo diferenças marcantes. As semelhanças incluem a aplicação de conceitos de marketing em suas ações, a avaliação constante da mídia e da opinião pública externas, a ênfase na construção de relacionamentos e confiança com o público-alvo, o monitoramento e a interação com os meios de comunicação locais, e o uso da mídia para difusão de mensagens e conceitos, incluindo cada vez mais as mídias eletrônicas, o que, no caso da prática diplomática, ganhou campo de atuação específico, o da diplomacia digital ${ }^{6}$.

As distinções, por sua vez, abarcam o alcance das metas e dos resultados, uma vez que a diplomacia pública lida com questões mais complexas e multifacetadas do que os aspectos meramente comerciais do marketing internacional de produtos ou serviços e deve inserir suas ações, bem como basear suas decisões, nas diretrizes da política externa. Além disso, a diplomacia pública pode operar e valer-se de outros instrumentos, muitas vezes mais sutis e focados do que as tradicionais ferramentas de marketing internacional, exemplificadas pelas grandes campanhas de marca-país com utilização maciça da mídia, para atingir os objetivos de alterar as percepções de atores -chaves no mercado local.

Na diplomacia, como enfatiza Leonard (2002), a construção do relacionamento e de confiança ganha conotação importante, por meio do entendimento das necessidades dos outros governos, culturas e pessoas, da comunicação precisa de opiniões, da correção de percepções equivocadas, da identificação de áreas comuns para cooperação. Para Leonard, a especificidade da diplomacia pública consiste em envolver grupo mais abrangente de indivíduos e gama maior de interesses, que vão além dos interesses estatais e da interação intergovernamental, objeto precípuo da diplomacia tradicional.

Szondi (2008) argumenta que a meta primordial da diplomacia pública reside no ato de influenciar a opinião de uma população estrangeira, ao criar ambiente receptivo para os objetivos da política externa e para a promoção dos interesses nacionais. A diplomacia pública, para o autor, concentraria seus esforços em segmentos específicos, como as elites culturais e políticas, formadores de opinião e líderes, na medida em que a gestão da marca-país seria voltada à audiência de massa.

Embora a diplomacia pública tenha objetivos mais extensos do que a gestão de marca-país, é muito comum que suas ações abarquem aquelas relacionadas ao desenvolvimento e gestão da marca-país, com as diferenças já explicitadas nos parágrafos anteriores. Tampouco é raro que ações de diplomacia pública conduzidas pelas chancelarias e campanhas de marketing internacional administradas por outros órgãos de governo somem esforços, de modo a surtir resultados de maior impacto no público do país-alvo. Em síntese, como argumenta Gilboa $(2008,68)$, diplomacia pública não pode ser reduzida a "slogans e imagens”, ao mesmo tempo em que como sugere Wang $(2006,93)$ "gerir a reputação da nação” é objetivo basilar dessa prática diplomática. Anholt (2006) argumenta que não há como ter gestão de marca-país efetiva dissociada do uso de instrumentos de diplomacia pública, tanto que a revista científica "Place Branding”, criada pelo autor em 2004, alterou seu nome, em 2006, para "Place Branding and Public Diplomacy”.

A imagem dos países influencia, irrefutavelmente, a decisão de consumidores, investidores, migrantes qualificados e parceiros internacionais em todas as áreas, incluindo a tecnológica. Para tanto, a diplomacia pública, como

\footnotetext{
${ }^{6}$ Gilboa (2016) explica que diplomacia digital é termo decorrente da necessidade de explicar e analisar os efeitos das tecnologias de informação e comunicação, em particular da Internet e de mídias sociais, na condução da política externa e diplomacia. Segundo o autor, é prática diplomática que utiliza tecnologias da informação e comunicação como instrumento para atingir as metas da política externa de atores estatais e não-estatais.
} 
parte fundamental dos esforços da gestão da marca-país, deveria dedicar cada vez mais espaço na promoção do segmento tecnológico em ações de internacionalização e de promoção de imagem, em vista das externalidades positivas que o setor gera para a economia nacional, a qual, a seu turno, será crescentemente digitalizada e baseada no conhecimento. Trata-se de setor estratégico para alavancar a competitividade de toda a economia brasileira.

Com amparo nesses entendimentos, faz todo o sentido a construção de programa específico pela chancelaria brasileira, a fim de articular a atuação diplomática em prol da difusão e gestão da imagem do Brasil como país inovador.

\section{Posicionamento e gestão da imagem de um país inovador}

A gestão da imagem de um país é muito mais do que a elaboração e disseminação de logomarcas ou de slogans. Para que um país atinja êxito na gestão da imagem, a despeito da decisão de associá-la à inovação, deve construir estratégia que envolva e seja validada e reconhecida como legítima por todos os segmentos da sociedade, e que se posicione de forma diferenciada frente a outras nações (FAN, 2010). Deliberar esse posicionamento de marca-país alicerçado no consenso da sociedade não é tarefa trivial. Em geral, trata-se de exercício cuja condução recai nos governos.

Lee (2009), ao estudar os casos da Coreia do Sul e Irlanda, criou modelo de gerenciamento alicerçado nas seguintes etapas: (i) alinhar a marca-país com a estratégia nacional; (ii) posicionamento da marca-país; (iii) construção da estratégia de marca-país; (iv) gestão da imagem.

Independente da estratégia utilizada pelos países para construção e gestão da imagem no exterior que se enquadraria nesse modelo de Lee (2009), a padronização da comunicação das múltiplas dimensões da marca-país faz-se necessária para posicionamento frente a “competidores”. A gestão de imagem implica, portanto, coordenação das diversas narrativas comunicadas pela miríade de agentes governamentais, numa pluralidade de áreas, e requer a observação de certas condições quando se trata de tecnologia e inovação, a fim de que a estratégia venha a maximizar ganhos e reduzir eventuais riscos.

Quando a marca-país quer ser associada ao setor tecnológico, é forçoso que seus administradores e operadores, sejam membros do governo ou indicados por eles, interajam constantemente com a comunidade científica e de empreendedorismo inovador, a fim de que as iniciativas de promoção tenham a ressonância almejada perante os formadores de opinião qualificados. Trata-se de algo diverso da prática tradicional da diplomacia pública que relega aos diplomatas o planejamento, organização e execução de suas ações como seminários, festivais, advocacia pública entre outros.

A gestão da imagem de um país inovador, portanto, não pode ser conduzida somente pelas chancelarias ou por agências de promoção de exportação e atração de investimentos, mas deve envolver os atores que integram os sistemas nacionais de ciência, tecnologia e inovação, sob pena de não gerar os efeitos desejados, mesmo em se tratando apenas de diplomacia pública. Não só se deve manter consultas constantes com esses agentes que propiciam conhecer as demandas do setor, bem como identificar quais as estratégias que rendem resultados mais eficazes, mas também se deve inserir esses atores em todas as fases da gestão da imagem, desde a formulação de estratégias, planejamento, organização e execução de ações no exterior. Governo, academia, setor privado e sociedade, a chamada hélice quádrupla (Carayannis; Campbell, 2009), deve atuar no sentido de administrar a marca de um país tecnológico.

Feita a reflexão de que faz sentido incorporar na estratégia de marca-país o posicionamento como nação tecnológica, faz-se premente analisar se esse posicionamento encontra respaldo nos tecidos produtivo e, sobretudo, científico e empreendedor. A tarefa torna-se mais desafiadora quando há percepções internacionais equivocadas ou mesmo a ausência de percepções em relação ao potencial tecnológico de um local. Anholt (2005) é um dos diversos autores que destacam as dificuldades de empresas que não se alinham às imagens de suas nações na promoção de seus produtos ou serviços no exterior. Cita o caso da italiana Olivetti, empresa de tecnologia em meio a um país ligado à moda, e a Hugo Boss, empresa de moda alemã, que luta contra as percepções dominantes relacionadas à Alemanha como produtora de 
máquinas. O fenômeno de marcas globais que transcendem a reputação de seus lugares de origem é algo muito raro. É, portanto, salutar e de interesse das próprias empresas que seus segmentos estejam contemplados tanto no posicionamento quanto na gestão da marca-país.

Uma das decisões na estratégia a ser definida na construção da marca-país como nação inovadora será se haverá recorte no segmento tecnológico, como realizado pela Estônia e pela Índia, ao concentrar seus posicionamentos de marca em tecnologias digitais, ou se o país adotará o posicionamento mais genérico da inovação tecnológica impregnada em todos os segmentos, como Suécia, Suíça e Reino Unido. Vale, portanto, análise mais apurada desses modelos para compreensão das estratégias adotadas e para extração de lições e boas práticas.

\section{Experiências internacionais}

Um dos países que lograram reinventar a sua identidade no transcurso de algumas décadas é a Estônia, que se intitula a primeira "nação digital”. O país lançou campanha com jogo de palavras ao inserir o "e -" na frente de seu nome, o que remete o imaginário coletivo para o mundo virtual. A “e-Estonia” é iniciativa executada pela "Enterprise Estonia”, a agência de promoção de exportações e atração de investimentos daquele país, criada em 2000, ligada ao Ministério de Assuntos Econômicos. O conceito do “e-Estonia” (PAPP-VÁVRY, 2018) posiciona o país na vanguarda das tecnologias digitais, ao ser um dos primeiros a adotar o voto digital, por meio da identidade digital dos cidadãos, e até mesmo a instauração de uma cidadania digital. A marca-país relacionada à uma "nação digital” tem forte aderência em todo o tecido social estoniano, cuja sociedade e governo percebem o valor do reconhecimento internacional de seu país ligado a soluções digitais de impacto. A repercussão alcançada pelo pequeno país do Báltico pode ser considerada caso de sucesso tanto na construção de posicionamento de marca internacional ligada ao setor tecnológico quanto na sua gestão de imagem.

A Índia é outro país que estabeleceu objetivos muito claros de transformação digital de sua economia englobados na campanha "Digital India". Lançado em 2015, o programa envolve toda a estrutura governamental indiana com a coordenação do gabinete do primeiro-ministro e a execução pelo Departamento de Eletrônica e Tecnologia da Informação da Índia. A estratégia está focada em três eixos prioritários: (i) criação de infraestrutura digital para todos os cidadãos; (ii) garantia do oferecimento de serviços governamentais digitais, e (iii) empoderamento digital dos cidadãos. Kedar (2015) considera o "Digital India" como o mais ambicioso programa de divulgação conduzido pelo governo indiano para elevar o patamar do reconhecimento de suas competências digitais tanto pela audiência interna quanto pela externa. Para o autor, o programa teria o objetivo geral de melhorar a imagem global do país e, em particular, ressaltar as vantagens comparativas de seu mercado com vistas a atrair investimentos para o setor tecnológico e formar parcerias estratégicas. No diálogo com os agentes estrangeiros, a Chancelaria indiana recorre a instrumentos de diplomacia pública para firmar a marca-país associada à inovação com a divulgação do "Digital India”. Essa atuação diplomática acontece em paralelo à promoção de outras vertentes da imagem do país, como a campanha “Incredible India” na área de turismo.

Outro país cuja reputação internacional associada ao setor tecnológico foi construída nas últimas décadas é a Suécia. O país, contudo, não vinculou sua marca especificamente a um setor, como a Estônia e a Índia. A Suécia (2017) criou órgão específico, em 2013, para tratar e coordenar as ações de imagem do país no exterior de longo prazo, bem como traçar a estratégia de promoção da marca-país. Trata-se do “Conselho para a Promoção da Suécia”, composto pelo Ministério dos Negócios Estrangeiros, Ministério da Empresa e Inovação, Ministério da Cultura, Instituto Sueco, ‘Business Sweden’ e ‘Visit Sweden'. O conselho definiu que a estratégia deveria girar em torno de quatro áreas: inovação, criatividade, sociedade e sustentabilidade, caracterizada por quatro valores fundamentais, a saber: inovador, aberto, solidário e autêntico. Nessas condições, as ações de promoção no exterior executadas por missões diplomáticas e consulares devem se pautar por essas diretrizes. As orientações são seguidas não só pelo governo, mas também por organizações privadas e empresas suecas que, ao agir em conjunto, fortalecem a marca que beneficiará a todos esses segmentos. O portal eletrônico 'Sharing 
Sweden', coordenado pelo Ministério dos Negócios Estrangeiros, reúne o material audiovisual e o conteúdo para guiar a divulgação da estratégia de promoção, que tem em inovação um dos seus eixos.

Da mesma forma que a Suécia, a Suíça, outra nação que se encontra no topo de rankings internacionais de inovação, também criou entidade para definir o posicionamento e traçar a estratégia da marca, gerenciar a comunicação da imagem do país no exterior, e proteger seus interesses por intermédio de ferramentas de relações públicas: a 'Presence Switzerland' (SCHLEGEL, 2014). Criada em 2001 e liderada pela chancelaria suíça, a instituição busca coordenar a atuação dos mais diversos entes públicos e privados, ao disponibilizar o material de comunicação, no qual a inovação tecnológica ganha papel de destaque, sem singularizar setores específicos. A estratégia de comunicação no exterior implementada pela 'Presence Switzerland', conjuntamente com as representações do governo suíço, é aprovada pelo Conselho Federal do país por um período de quatro anos.

$\mathrm{Na}$ "Estratégia Nacional para a Comunicação no Exterior 2016-2019”, além dos objetivos gerais de difundir conhecimento sobre o país, a Suíça definiu três características específicas de como o país gostaria de ser percebido pelo olhar estrangeiro, a saber: (i) inovador e competitivo, (ii) solidário e responsável; (iii) com alto nível de qualidade de vida e atrativo para negócios.

O Reino Unido foi outro país que colocou a inovação como parte central de sua narrativa no exterior de posicionamento da marca-país na campanha “GREAT" (REINO UNIDO, 2020), lançada em 2012, por ocasião dos Jogos Olímpicos de Londres, e que buscou um jogo de palavras com o nome em inglês de Reino Unido ('Great Britain') para transmitir os vários aspectos que seriam "incríveis". Ainda que a campanha abranja diversos segmentos, o "Innovation is Great” permeia diversas mensagens, ao enfatizar as capacidades tecnológicas, de pesquisa e educacionais do país, e ao buscar associá-lo à modernidade, à criatividade e às indústrias dinâmicas de alta tecnologia. Não há, contudo, a escolha de segmento tecnológico específico para a concentração dos esforços de divulgação. A campanha é executada pelo Departamento de Comércio do Reino Unido, mas se articula com os mais diversos órgãos de governo e com o setor privado por meio de comitê interinstitucional, do qual a chancelaria britânica faz parte, para construir narrativa integrada no exterior.

O que se percebe da avaliação da atuação dos modelos acima é o papel exercido pelas chancelarias, muitas vezes associadas a agências de promoção de investimentos, negócios e turismo, com a utilização de instrumentos de diplomacia pública, em maior ou menor grau, para que sejam alcançados os resultados almejados em termos de promoção da imagem no exterior, ainda que em segmento com muitas especificidades técnicas, como o tecnológico. Outra constatação é a de que os países construíram suas reputações baseadas na projeção no plano internacional de setores ou características que sobressaem nos planos nacionais.

O Brasil, considerado país com população criativa e inovadora por natureza (ANHOLT, 2007), dotado de capacidades de produção tecnológica em diversas áreas (BOUND, 2008), detém as credenciais necessárias para ressaltar na promoção de sua marca-país no exterior a característica de país tecnológico e inovador, tal como os exemplos internacionais analisados nesta seção.

\section{Potencial de desenvolvimento da marca de um Brasil tecnológico e inovador}

Há consenso de que a inserção internacional do Brasil depende de imagem adequada no exterior. Amaral (2006, p. 9) advoga que:

A aspiração legítima em assumir novas responsabilidades e funções relevantes no processo decisório internacional, a possibilidade de atrair investimentos de qualidade, ampliar o número de turistas estrangeiros ou agregar valor aos produtos de exportação, entre outros objetivos, dependem da capacidade de falar não apenas aos governos, mas também à sociedade: à mídia, aos meios culturais, aos agentes econômicos, às instituições da sociedade civil, assim como a eleitores e consumidores. A 
construção da Marca Brasil, sobre a qual muito se fala, mas pouco se faz, tornou-se uma pré-condição para o êxito da inserção econômica do Brasil no plano internacional.

Em termos de percepção internacional sobre o Brasil, ainda que haja muito desconhecimento sobre a realid ade nacional, há sentimentos positivos. Anholt (2007) defende que: “o Brasil possui uma marca naturalmente muito forte. Não interessa a quem ou onde você pergunte sobre o Brasil: samba, futebol, carnaval, música, dança, felicidade, praia e aventura serão alguns dos atributos mencionados pelas pessoas em referência ao Brasil”. Não obstante, embora todos queiram ser “amigos” de brasileiros, quando se trata de negócios, ainda imperam estereótipos negativos. A transmissão de imagem de país inovador e na fronteira científica em algumas tecnologias esbarra não só apenas em preconceitos, mas em desconhecimento generalizado das capacidades inovadoras brasileiras, o que acarreta reflexos negativos na atração de investimentos e talentos para o setor de inovação tecnológica e formação de parcerias para a cooperação internacional. Parte desse desconhecimento pode ser atribuído à baixa internacionalização da economia brasileira.

De Negri, Rauen e Squeff (2018) traçam diagnóstico de que o Brasil ainda apresenta poucas conexões com os ecossistemas de inovação mais dinâmicos, o que prejudica a inserção nessas redes de conhecimento, ideias, descobertas e negócios. O insulamento nacional inibe o potencial inovador da economia. A capacidade científica e tecnológica brasileira permite que os pesquisadores e empreendedores participem em termos equânimes em diversas áreas do conhecimento com contrapartes internacionais (REYNOLDS; SCHNEIDER; ZYLBERBERG, 2019). Em muitos casos, a ciência brasileira está à frente da maioria dos países, como em exploração de águas profundas. Não se trata, com efeito, de criar artificialmente uma marca-país relacionada à inovação, mas de comunicar efetivamente a realidade para formadores de opinião, tomadores de decisão e potenciais parceiros tecnológicos e comerciais no exterior.

É premente, nessas condições, elaborar estratégia de longo prazo e estabelecer uma gestão de imagem eficaz, de modo a que a percepção externa do Brasil reflita o potencial do empreendedorismo inovador da nação. Embora não haja política pública articulada de divulgação da imagem de país inovador no exterior, pois o Programa de Diplomacia da Inovação ainda é uma iniciativa do MRE, há mecanismo responsável pela coordenação da comunicação do Governo Federal, o Sistema de Comunicação de Governo do Poder Executivo Federal (SICOM), que poderia assumir as funções de formular e executar a estratégia para a marca-país, que inclua inovação como um de seus principais componentes.

O SICOM, cuja estrutura remonta do final da década de $1960^{7}$, é integrado pelo Ministério das Comunicações ${ }^{8}$, como órgão central, e pelas unidades administrativas dos órgãos e entidades integrantes do Poder Executivo Federal que tenham a atribuição de gerir ações de comunicação, como as assessorias de comunicação dos ministérios e de empresas públicas. O Decreto n⿳0 6.555, de 8 de setembro de 2008, dispõe sobre as ações de comunicação do Poder Executivo Federal, seus objetivos e diretrizes, entre os quais a promoção do Brasil no exterior, e estabelece a elaboração de planos anuais de comunicação pelos integrantes do SICOM.

Ao Ministério das Comunicações, por meio de sua Secretaria de Comunicação Institucional, compete, além da coordenação do SICOM e do relacionamento com a imprensa internacional, "coordenar as ações de comunicação da República Federativa do Brasil no exterior, em articulação com os demais intervenientes.” No âmbito da estrutura da Secretaria de Comunicação Institucional daquele Ministério encontra-se o Departamento de Comunicação Internacional,

\footnotetext{
${ }^{7}$ Segundo informações veiculadas na página eletrônica do Ministério das Comunicações, em 1967, o Decreto-Lei nº 200 estabeleceu regras sobre os sistemas de atividades auxiliares do Governo Federal, base para a instituição do que hoje conhecemos como o Sistema de Comunicação de Governo do Poder Executivo Federal, o SICOM. Chamado, inicialmente, de Sistema de Comunicação Social do Poder Executivo, pelo Decreto no 67.611/1970, o sistema tinha o encargo de formular e aplicar a política capaz de, no campo interno, predispor, motivar e estimular a vontade coletiva para o esforço nacional de desenvolvimento e, no campo externo, contribuir para o melhor conhecimento da realidade brasileira, sendo seu órgão central a Assessoria Especial de Relações Públicas da Presidência da República. A Lei no 6.650 de 1979 criou, na Presidência da República, a Secretaria de Comunicação Social (SECOM/PR), à qual se vinculava a Empresa Brasileira de Radiodifusão (Radiobrás). Além disso, converteu a Agência Nacional em empresa pública, a denominada Empresa Brasileira de Notícias (EBN).

${ }^{8}$ A Secretaria de Comunicação Social, ligada à Presidência da República, era o órgão central do SICOM, mas foi incorporado, pela Lei no 14.074 , de 14 de outubro de 2020, à estrutura do Ministério de Comunicações, cuja competência expressa é a da "política de comunicação e divulgação do Governo federal”.
} 
o qual é responsável por "elaborar plano de comunicação internacional, em articulação com as demais áreas do Ministério, de modo a divulgar políticas, programas e ações do Governo federal junto ao público estrangeiro”.

Fica claro que as atribuições do Ministério das Comunicações incluem a formulação da estratégia brasileira de marca-país, bem como a gestão da imagem do Brasil no exterior. Deve-se, contudo, ressalvar que, conforme discutido nesta seção, no segmento tecnológico e de inovação, é imperioso reunir todos os atores do sistema brasileiro de ciência, tecnologia e inovação no processo decisório para formular essa estratégia e, em sua execução, é mister que o Ministério das Relações Exteriores, em vista da diplomacia pública que exerce, seja um dos protagonistas na elaboração e gestão dessa imagem.

O corpo diplomático, por estar em contato permanente com interlocutores de ecossistemas de inovação e formadores de opinião estrangeiros, além de conhecer as especificidades das sociedades locais, detém capacidades de influenciar e construir relacionamentos, que transcendem os objetivos das grandes campanhas de divulgação de marca país voltadas ao público em geral, como na área de turismo e cultura. Muitas vezes, essas ações customizadas direcionadas a nicho determinado, com objetivos definidos e restritos, podem ser mais eficazes para a formação de parcerias específicas e atração de investimentos, como parece acontecer no setor de tecnologia.

Quando se trata de promoção tecnológica, resta claro que a Chancelaria brasileira possui papel de articulador, e não de competidor, em relação a outras entidades públicas e privadas que também apoiam à internacionalização do SNCTI, à atração de investimentos, e à consequente busca de imagem positiva do País como nação inovadora. Essa capacidade fluida de diálogo é reconhecida pelos próprios atores do sistema, que buscam alinhar as suas respectivas atuações à política externa e à visão de longo prazo conduzida pelo Ministério das Relações Exteriores (MRE).

Com base nesse diagnóstico, o Programa de Diplomacia da Inovação (PDI) da Chancelaria brasileira foi criado para buscar quebrar os estereótipos negativos vinculados à imagem do Brasil no exterior e mostrar País que produz conhecimento, produtos e serviços em setores da fronteira científica, e que tem capacidade de ser referência mundial em certas tecnologias (SILVA, 2018).

Ao lançar programa como o de Diplomacia da Inovação, o Brasil não é pioneiro. Vários países buscam influenciar a percepção de agentes externos de modo a enaltecer as qualidades de seus setores de tecnologia e inovação, bem como fomentar parcerias com os atores mundiais mais relevantes. Diversas agências de promoção de exportações e investimentos ou instituições dedicadas a estimular conexões entre ecossistemas nacionais de inovação com congêneres estrangeiros mantêm escritórios no exterior, com o propósito de propiciar e facilitar ações de divulgação dos potenciais tecnológicos domésticos e aumentar o grau de internacionalização de suas economias, como a Vinnova, da Suécia; a Swissnex, da Suíça; a 'Science and Innovation Network', do Reino Unido; a 'Holland Innovation network', dos Países Baixos; e os Centros de Inovação da Dinamarca e da Alemanha.

A divulgação do potencial tecnológico inovador brasileiro tende a suprir as lacunas de informação sobre o Brasil e superar preconceitos, ao gerar percepções positivas não apenas em potenciais parceiros para a elaboração de projetos conjuntos, mas também em fundos de capital de risco ('venture capital'), em investidores-anjo e, ainda, no próprio consumidor final estrangeiro, que poderão associar ao Brasil a reputação de país produtor de soluções tecnológicas confiáveis e eficientes, o chamado "efeito país de origem”. Esses resultados, devido a barreiras culturais, linguísticas e outras falhas de mercado, não acontecem necessariamente sem a intervenção de agentes governamentais.

O PDI pode vir a ser um dos braços executores de uma estratégia nacional de marca-país associada a país inovador, em linha com a Política Nacional de Inovação. Essa proposta, ao adotar o componente de inovação tecnológica, pode ser gestada entre os integrantes do SICOM, já que MCTI, MRE e outros órgãos ligados à promoção tecnológica são entidades que participam do sistema. O que se julga imperioso é que a estratégia de marca-país seja não só formulada, mas também executada por todos os entes da administração pública, federal e estadual, e mesmo do setor privado. 
Nessas condições, a divulgação do país como nação inovadora não deve ser tarefa apenas do Ministério das Comunicações ou do MRE, por meio do PDI, ou do MCTI, cujas atribuições estão mais evidentemente ligadas à inovação, mas de todos os ministérios e agências governamentais. Assim, o Ministério da Agricultura, Pecuária e Abastecimento (MAPA), ao promover o agronegócio, deveria promover a imagem do Brasil com um agronegócio inovador, o Ministério de Minas e Energia (MME), ao promover um Brasil com mineração sustentável e de energia limpa, deveria ressaltar o componente tecnológico, a EMBRATUR, ao promover o Brasil como destino turístico, deveria destacar as características de inovação tecnológica da nação.

Para que seja eficaz, a gestão da marca-país deve englobar todo o governo e, em princípio, poderia ser articulada pelo SICOM, em coordenação estreita com a Câmara de Inovação, instituída pelo Decreto n $10.534 / 2020^{9}$.

\section{Considerações finais}

O posicionamento da marca-país, formulação de estratégia, e estabelecimento de sua gestão e governança são componentes indissociáveis de política pública eficaz que consolide no cenário internacional a imagem de determinada nação. Seriam, portanto, necessárias ações adicionais, além daquelas propostas pelo MRE, por meio do PDI, para que o Brasil tenha política eficiente de promoção da marca-país no exterior, entendimento que é corroborado pelos casos internacionais estudados. No entanto, essas constatações não diminuem o mérito da proposta de programa implementada pelo MRE, uma vez que está alinhada com a prática de outras chancelarias e governos na promoção da imagem dos países e seria elemento importante inserido no âmbito de política mais abrangente, fruto de esforço de toda a sociedade brasileira.

Apenas quando o Brasil for reconhecido no plano internacional como um país tecnológico e inovador, é que outros países irão reconhecer nas instituições e empresas brasileiras um valor para a formação de parcerias. Não é à-toa que a promoção do Brasil no cenário internacional como país inovador foi considerada uma das estratégias para o cumprimento das diretrizes estabelecidas na Política Nacional de Inovação. Não se trata, igualmente, de desejo ufanista pelo mero reconhecimento de outras nações. Os baixos níveis de percepção de desenvolvimento tecnológico e da qualidade de capital humano brasileiros causam problemas no lado real da economia. Empresas cujos produtos estão associados à tecnologia, à inovação e ao alto grau de digitalização terão mais dificuldade em ter sucesso em seus processos de internacionalização se persistir preconceitos em relação ao próprio Brasil. Por meras questões de marketing, as empresas e entidades brasileiras podem ficar atrás de competidores estrangeiros que, a despeito de apresentar qualidade e eficiência inferior em seus produtos, serviços e processos, gozam de "melhor reputação" respaldada unicamente na percepção atrelada à marca -país de onde provém sua nacionalidade, o efeito "país-de-origem".

O diagnóstico é o de que esses preconceitos negativos em relação ao Brasil são decorrentes do hiato de conhecimento sobre a realidade, pois não refletem as reais condições dos ecossistemas brasileiros de inovação. Uma das razões desse desconhecimento é o baixo grau de internacionalização da economia brasileira, que não é apenas mensurado pela expansão de suas empresas e organizações ao exterior, mas, principalmente, pelo grau de conectividade com outras economias. Quanto mais “internacionalizado” é um país, mais conhecido será pela comunidade internacional. O estímulo à maior internacionalização de empresas de base tecnológica, institutos de pesquisa e ambientes de inovação contribui para a difusão do potencial tecnológico e inovador da realidade brasileira.

A política externa, como política pública ${ }^{10}$ que é, teria a responsabilidade de atender essa demanda proveniente não só das estruturas de governo, mas de toda a sociedade brasileira e criar mecanismos para buscar solucionar o problema. O Programa de Diplomacia da Inovação tem o propósito, assim, de melhorar a percepção de interlocutores

\footnotetext{
${ }^{9}$ A Câmara de Inovação é órgão deliberativo destinado a estruturar e a orientar a operacionalização dos instrumentos e dos processos necessários para a implementação da Política Nacional de Inovação e sua composição abarca representantes de 11 instituições.

${ }^{10}$ Lafer (2007) defende que: “A política externa é uma política pública. Interessa a todos, pois trata da gestão dos interesses coletivos de uma nação no mundo. (...) Na definição de metas de política externa é relevante identificar com sentido de prioridade o que um país realmente precisa obter no plano internacional para atender as suas necessidades internas.”
} 
estrangeiros em relação às potencialidades tecnológicas brasileiras, ao promover o Brasil no cenário internacional como nação inovadora e, assim, consolidar a marca-país associada ao setor de tecnologia.

Trata-se de decisão acertada da chancelaria brasileira, uma vez que atividades isoladas dificilmente alterarão a percepção em relação à reputação de um país, mas uma série de iniciativas podem, em conjunto, influenciar o entendimento relacionado às potencialidades brasileiras e facilitar a formação de parcerias, atração de investimento e talentos para o Brasil. Esse é o fundamento da importância da elaboração de programa estruturado de divulgação da imagem do Brasil como um país tecnológico, que ensejará decurso de tempo considerável até surtir os efeitos almejados.

O SICOM, conforme defendido neste artigo, poderia ser a entidade a concentrar o processo decisório da política de marca-país e orientar os órgãos de governo em relação à marca Brasil como nação inovadora, além de monitorar as entregas de cada unidade. Para que se atinja o objetivo de consolidação da marca-país ligada ao setor de tecnologia inovadora, as ações desenvolvidas no âmbito do PDI não são suficientes. O programa, não obstante ser considerado uma política pública eficaz e alinhada com as boas práticas internacionais, não ganhará maior envergadura e logrará surtir o efeito desejado de reconhecimento no exterior do Brasil como país inovador se não for resultado de esforço coletivo maior, e de política implementada por todo o governo e sociedade brasileira.

O Brasil, a despeito de esforços realizados, ainda apresenta baixo grau de internacionalização sendo pouco reconhecido como um 'hub' tecnológico internacional. É possível, contudo, lograr atingir o reconhecimento internacional de um Brasil tecnológico e inovador no exterior, desde que haja definição das políticas relacionadas à marca-país e esforços sistemáticos de promoção no exterior por todo o SNCTI.

\section{Referências}

AMARAL, Sérgio. Uma política externa para o Século XXI. Política Externa. vol.15, n. 2, p.7-20, 2006.

ANDREUCCI CURY, Maria Cecília. Marca-País como Entidade Semiótica: A construção simbólica da Marca Brasil. Tese de Doutorado em Ciências da Comunicação - Pós-Graduação em Ciências da Comunicação - Universidade de São Paulo, São Paulo, 2015.

ANHOLT, Simon. Brand New Justice: how branding places and products can help the developing world. Oxford: Elsevier ButterworthHeinemann, 2005.

ANHOLT, Simon. Public diplomacy and place branding: Where’s the link? Place Branding, vol. 2, n. 4, p. 271-275, 2006.

ANHOLT, Simon. Competitive Identity: the new brand management for nations, cities and regions. New York: Palgrave Macmillan, 2007.

BAINES, Paul.; O’SHAUGHNESSY, Nicholas. Political marketing and propaganda: Uses, abuses, misuses. Journal of Political Marketing, vol.13, n.1/2, p.1-18, 2014

BARROSO, Nilo. Diplomacia Pública: Conceitos e Sugestões para a Promoção da Imagem no Exterior. Brasília, DF: LI CAE, IRBr, 2007.

BOUND, Kate. Brasil: a economia natural do conhecimento. Brasília: Centro de Gestão e Estudos Estratégicos, 2008.

BRASIL. Programa de Diplomacia da Inovação. MRE. Disponível em: <http://www.itamaraty.gov.br/pt-BR/politica-externa/cienciatecnologia-e-inovacao/124-programa-de-diplomacia-da-inovacao > Acesso em: 27 nov. 2019.

BRASIL. Lei no 14.074, de 14 de outubro de 2020. Altera a Lei no 13.844 , de 18 de junho de 2019, para criar o Ministério da Ciência, Tecnologia e Inovações e o Ministério das Comunicações.

BRASIL. Decreto no 10.534, de 28 de outubro de 2020. Institui a Política Nacional de Inovação e dispõe sobre a sua governança.

BRASIL. Constituição (1988). Constituição da República Federativa do Brasil. Brasília: Senado Federal, 1988. Disponível em: <https://goo.gl/FzXHXP>. Acesso em: 4/05/2020.

BRIJS, Kris. The CoO-ELM model: A theoretical framework for the cognitive processes underlying country of origin-effects. European Journal of Marketing, vol. 43, n. 1/2, p. 62-69, 2009.

CARAYANNIS, Elias; CAMPBELL, David. 'Mode 3' and 'Quadruple Helix': toward a 21st century fractal innovation ecosystem. International Journal of Technology Management, v. 46, n. 3-4, p. 201-234, 2009. 
DE NEGRI, Fernanda.; RAUEN, André; SQUEFF, Flávia. Ciência, Inovação e Produtividade: por uma nova geração de políticas públicas. In: DE NEGRI, João Alberto; ARAÚJO, Bruno; BACELETTE, Ricardo (Orgs.). Desafios da nação: artigos de apoio. Brasília: Ipea, 2018.

DINNIE, Keith. Nation Branding: concepts, issues, practice. 1st edition. Oxford: Elsevier, 2008.

DINNIE, Keith. City Branding: theory and cases. Londres: Palgrave MacMillan, 2011.

ESTONIA. e-Estonia guide. Disponível em: <https://e-estonia.com/wp-content/uploads/eestonia-vihik-a5-200303.pdf>. Acesso em: $26 / 06 / 2020$.

GILBOA, Eytan. Diplomacy in the media age: Three models of uses and effects. Diplomacy \& Statecraft, v. 12, n. 2, p. 1-28, 2001.

GILBOA, Eytan. Searching for a Theory of Public Diplomacy. The Annals of the American Academy of Political and Social Science, vol. 616, p. 55-77, 2008.

GILBOA, Eyta. Digital Diplomacy. In Constantinou, C.; Kerr P.; Sharp, P., The Sage Handbook of Diplomacy. Thousand Oaks, CA: Sage, p. 540-551, 2016.

FAN, Ying. Branding the nation: Towards a better understanding. Place Branding and Public Diplomacy, vol. 6, n. 2, p. 97-103, 2010.

FRIMPONG, Kwabena; AUSTIN, Nathan. Country-Branding - A developing economy perspective. International Journal of Business Strategy, vol. 11, n. 2, p. 123-131, 2011.

GILMORE, Fiona. A country - can it be repositioned? Spain - the success story of country branding. Brand Management, vol. 9, n. 4-5, p. 281-293, 2002.

GÜNEK, Abdulsamet. A new type of soft power: country branding. International Journal of Cultural and Social Studies, vol. 4, n. 1, p. 252-259, 2018.

HAM, Peter. The Rise of the Brand State: The Postmodern Politics of Image and Reputation. Foreign Affairs. vol. 80, n. 5, p. 2-6, 2001.

HAKALA, Ulla, LEMMETYINEN, Arja; KANTOLA, Satu-Päivi. Country image as a nation-branding tool. Marketing Intelligence \& Planning, vol. 31, n. 5, p. 538-556, 2013.

INDIA. Digital India Programme. Department of Electronics \& Information Technology. Disponível em: $<$ http://www.digitalindia.gov.in/>. Acesso em: 12/07/2020.

KEDAR, Maheshkumar. Digital India New way of Innovating India Digitally. International Research Journal of Multidisciplinary Studies, vol. 1, n. 4, p. 64-70, 2015.

LAFER, Celso. Novas variações sobre a política externa. O Estado de São Paulo, Espaço Aberto, p. A2, 15/12/2007.

LEE, Kim. Nation Branding and Sustainable Competitiveness of Nations. Tese de Doutorado em Administração e Ciências Sociais Faculdade de Comportamento. Universidade de Twente, Twente, 2009.

LEONARD, Mark. Public Diplomacy. Londres: The Foreign Policy Centre, 2002.

MARIUTTI, Fabiana. Reflections on the challenging mission of the country brand construct in the international business setting. Review of International Business ESPM. São Paulo, v.10, n. 3, p. 58-70, 2015.

MELISSEN, Jan. Wielding Soft Power: the New Public Diplomacy. The Hague, Netherlands Institute of International Relations Clingendael. Clingendael Diplomacy Paper nº 2, 2005.

MONTANARI, Maria Gabriela.; GIRALDI, Janaína. A theoretical study on country brand and its management. Review of International Business ESPM. São Paulo, v.13, n. 2, p. 14-29, 2018.

MOURA, Liliam. A marca Brasil: o poder da imagem e a construção da identidade competitiva. Brasília, DF: LVIII CAE, IRBr, 2013.

NYE, Joseph. Public Diplomacy and Soft Power. The Annals of the American Academy of Political and Social Science, vol. 616, p. 94 $109,2008$.

OLINS, Wally. Branding the Nation - the historical context. The Journal of Brand Management, vol. 9, n. 4/5, p. 241-248, 2002.

PARAIZO, André. Análise da Marca "Brasil” à luz dos conceitos de país de origem e de país como marca. Dissertação de Mestrado Profissionalizante em Administração - Faculdade de Economia e Finanças Ibmec - Programa de pós-graduação e pesquisa em Administração e Economia, Rio de Janeiro, 2007.

PAPP-VÁRY, Árpád. A Successful Example of Complex Country Branding: The 'E-Estonia' Positioning Concept and Its Relation to the Presidency of the Council of the EU. Acta Univ. Sapientiae, European and Regional Studies, vol. 14, p. 87-115, 2018.

REINO UNIDO. Great Britain Campaign. Disponível em: <https://www.greatbritaincampaign.com/>. Acesso em: 27/06/2020. 
REYNOLDS, Elisabeth.; SCHNEIDER, Ben.; ZYLBERBERG, Ezequiel. (orgs.) Innovation in Brazil: advancing development in the 21st century. London and New York: Routledge, 2019.

SAME, Siiri.; SOLARTE-VASQUEZ, Maria Cláudia. Country Branding and Country Image: Insights, Challenges and Prospects. The Case of Estonia. Baltic Journal of European Studies, vol. 4, n. 1, p. 137-165, 2014.

SCHLEGEL, Flavia. Swiss Science Diplomacy. Science and Diplomacy, 2014. Diplofoundation. Disponível em: http://www.sciencediplomacy.org/perspective/2014/swiss-science-diplomacy. Acesso em: 06/04/20.

SOUZA, Eber et al. Brazil 's image: ten country similarities and differences assessment. Review of International Business. v.9, n.2, p.5974, 2014.

SILVA, Pedro Ivo. Fundamentos teóricos e práticos da Diplomacia da Inovação. Caderno de Política Exterior, vol. 4, n. 7, p. 307-330, 2018.

SZONDI, Gyorgy. The role and challenges of country branding in transition countries: the Central and Eastern European experience. Place Branding and Public Diplomacy, vol. 3, n. 1, p. 8-20, 2007.

SZONDI, Gyorgy. Public Diplomacy and Nation Branding: Conceptual Similarities and Differences. Discussion Papers in Diplomacy. Netherlands Institute of International Relations 'Clingendael', Antuérpia, 2008.

SUÉCIA. Strategy for the Promotion of Sweden 2.0. Swedish Institute/Ministry for foreign affairs, 2017. Disponível em: < https://sharingsweden.se/ >. Acesso em: 9/06/20.

SUÍÇA. Strategy for Communication Abroad 2016-2019. Disponível em: <https://www.eda.admin.ch/dam/eda/en/documents/daseda/landeskommunikation/strategie-landeskommunikation-2016-2019_EN.pdf >. Acesso em: 27/06/2020.

SUíçA. Switzerland seen from abroad in 2019. Disponível em: <https://www.eda.admin.ch/dam/eda/en/documents/daseda/landeskommunikation/PRS_2019_analyse_EN.pdf >. Acesso em:27/06/2020.

VILLANOVA, Carlos. Diplomacia pública e imagem do Brasil no século XXI. Brasília: FUNAG, 2017.

WANG, Jian. Managing national reputation and international relations in the global era: Public diplomacy revisited. Public Relations Review, vol. 32, n. 2, p. 91-96, 2006.

WHITE, Candance; KOLESNICOV, Iulia. Nation branding in a transitional democracy: the role of corporate Diplomacy in promoting national identity. Place Branding and Public Diplomacy, vol. 11, n. 4, p. 324-337, 2015. 